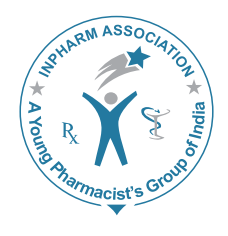

\title{
Studies on the Preparation, Characterization, and Solubility of 2-HP- $\beta$-Cyclodextrin-Meclizine HCI Inclusion Complexes
}

\author{
George SJ, Vasudevan DT \\ Department of Pharmaceutics, Amrita School of Pharmacy, AIMS Health Care Campus, Kochi, Kerala, India \\ Address for correspondence: Dr. Deepa T Vasudevan; E-mail: drdeepatv@gmail.com
}

\begin{abstract}
Meclizine $\mathrm{HCl}$ is a poorly water-soluble drug having a very slow-onset of action. The effect of 2-hydroxypropyl$\beta$-cyclodextrins and $\beta$-cyclodextrins on its aqueous solubility and dissolution rate was investigated. The phase solubility profile indicated that the solubility of Meclizine $\mathrm{HCl}$ was significantly increased in the presence of both 2-hydroxypropyl- $\beta$-cyclodextrin and $\beta$ - cyclodextrin; an extend of increase being more for 2-hydroxypropyl- $\beta$ cyclodextrin. It was classified as $A_{L}$-type, indicating the 1:1 stoichiometric inclusion complexes. The complexes formed were quite stable. The solid complexes prepared by physical mixtures, kneading methods, and co-precipitation methods were characterized using differential scanning calorimetry and FTIR. An in vitro study showed that the solubility and dissolution rate of Meclizine $\mathrm{HCl}$ were significantly improved by complexation with 2-hydroxypropyl$\beta$-cyclodextrin. Tablet formulation using 1:1 kneading complex of Meclizine $\mathrm{HCl}$ and 2-hydroxypropyl- $\beta$-cyclodextrin with drug equivalent to $25 \mathrm{mg}$ was prepared by a direct compression method. A dissolution study of prepared tablets was performed in $0.5 \%$ SLS in water (pH 7.0). Almost $96 \%$ drug was released from the formulation at the end of $30 \mathrm{~min}$. A comparison study of prepared tablets was done with marketed a Meclizine $\mathrm{HCl} 25 \mathrm{mg}$ conventional tablet. From the results of dissolution study, it was found that the prepared formulation was showing better release, which was statistically significant $P<0.01$ than a marketed tablet (paired $t$-test). Only $54 \%$ drug release was observed from the marketed tablet at the end of $30 \mathrm{~min}$. Hence this study concludes that the solubility enhancement of Meclizine $\mathrm{HCl}$ could be successfully achieved using the inclusion complexation technique.
\end{abstract}

Key words: 2-Hydroxypropyl- $\beta$-cyclodextrin, $\beta$-cyclodextrin, co-precipitation method, kneading method, phase solubility profile, Meclizine $\mathrm{HCl}$

\section{INTRODUCTION}

Meclizine is an antihistamine. It blocks the effects of the naturally occurring chemical histamine in our body.

\begin{tabular}{|l|l|}
\hline \multicolumn{2}{|c|}{ Access this article online } \\
\hline Quick Response Code: & \\
\hline & Website: \\
\hline & www.jyoungpharm.in \\
& DOI: \\
\hline & $10.4103 / 0975-1483.104365$ \\
\hline
\end{tabular}

Chemically, it is 1-(p-chloro-alpha-phenylbenzyl)-4 ( $m$-methylbenzyl)-piperazine dihydrochloride monohydrate. Meclizine is used to treat nausea, vomiting, and dizziness-associated with motion sickness. Meclizine may also be helpful in treating vertigo. Meclizine has CNS depressant, anticholinergic, antiemetic, antispasmodic, and local anesthetic effects in addition to antihistaminic activity. The drug depresses labyrinth excitability and conduction in vestibular-cerebellar pathways. The antiemetic and antimotion-sickness actions of the Meclizine result, at least in part, from its central anticholinergic and CNS depressant properties. Meclizine's antiemetic duration of action may last up to $24 \mathrm{~h}$ and has a 
half life of $6 \mathrm{~h}$. It produces less drowsiness as compared to other antihistamines of its class and also has longer duration of action. Meclizine has a lag of $1 \mathrm{~h}$ in the onset of action hence should be taken $1 \mathrm{~h}$ prior to travel for protection against motion sickness. ${ }^{[1-3]}$ This lag in the onset of action may be attributed to its poor solubility. The solubility of a poorly soluble drug can be altered in many ways, such as modification of drug crystal forms, addition of co-solvents, addition of surfactants, complexation with cyclodextrin, etc. Among these possibilities, the cyclodextrin approach is of particular interest. Meclizine $\mathrm{HCl}$ is very slightly soluble in water $(0.261 \mathrm{mg} / \mathrm{ml})$. In particular, Meclizine $\mathrm{HCl}$ exhibits very low solubility at $\mathrm{pH}$ values greater than 2.0 . The poor solubility and wettability of Meclizine $\mathrm{HCl}$ give rise to difficulty in pharmaceutical formulations meant for oral or parental use. To overcome these difficulties, an increase in the aqueous solubility of Meclizine $\mathrm{HCl}$ is an important goal, hence in this investigation solubility enhancement of Meclizine $\mathrm{HCl}$ was tried with 2-hydroxypropyl- $\beta$-cyclodextrin (HP- $\beta$-CD) and $\beta$-cyclodextrin $(\beta-C D)$ to find out which among the two cyclodextrins was more effective in enhancing its solubility. Moreover, inclusion complexation of the Meclizine $\mathrm{HCl}$ was tried using cyclodextrin with the aim to improve its pharmaceutical properties like aqueous solubility and dissolution properties.

Cyclodextrin are cyclic $(\alpha-1,4)$-linked oligosaccharides of $\alpha$-dglucopyranose, containing a relatively hydrophobic central cavity and hydrophilic outer surface. Owing to the lack of free rotation about the bonds connecting the glucopyranose units, the cyclodextrin are not perfectly cylindrical molecules but toroidal or cone shaped. Based on this architecture, the primary hydroxyl groups are located on the narrow side of the cone shape, while the secondary hydroxyl groups are located on the wider edge. During the past two decades, cyclodextrin and their derivatives have been of considerable interest in the pharmaceutical field because of their potential to form complexes with a variety of drug molecules. Cyclodextrin are used to increase the solubility of water-insoluble drug through inclusion complexes formulation. ${ }^{[4]}$ The hydrophobic cavity of cyclodextrin is capable of trapping a variety of molecules within to produce inclusion complexes. Many advantages of drugs complex with cyclodextrin have been reported in the scientific literature which includes increased solubility, enhanced bioavailability, improved stability, masking of bad test or odour, reduced volatility, transformation of liquid or gas into solid form, reduced side effect, the possibility of a drug release system, etc. ${ }^{[6-7]} 2$-Hydroxypropyl betacyclodextrin (HP $\beta-C D)$ is modified beta-cyclodextrin ( $\beta-C D)$ having a high aqueous solubility (about $60 \%$ ) and a proven safety profile, especially for parenteral use. ${ }^{[8]} \mathrm{HP}-\beta-\mathrm{CD}$ is produced from $\beta-C D$ by addition of propylene oxide to some of the hydroxyl groups of $\beta-C D$. This modification results in greater solubility of $\mathrm{HP}-\beta-\mathrm{CD}$ and its complexes compared to $\beta$-CD.

The solid-state characteristics of the drug after preparation and during storage will depend on the processing variables as well as the characteristics of the system. When the objective of the formulation is to attain faster dissolution rates, the presence of high energy amorphous form of drug would improve the dissolution rate of drug and also on the ability of the cyclodextrin to form soluble complexes with the drug. ${ }^{[9-11]}$ The performance of the product over the shelf life would depend on the ability of the cyclodextrin to prevent crystallization of the amorphous drug to its stable crystalline forms. ${ }^{[12]}$ In this study, the complex of Meclizine $\mathrm{HCl}$ with HP- $\beta-C D$ was prepared by using physical mixture, kneading method, and co-precipitation method at a 1:1 molar ratio. ${ }^{[13,14]}$ The characterization of drug with HP- $\beta-C D$ using DSC and FTIR, in vitro aqueous solubility and dissolution rate profile of complexes were performed. ${ }^{[15-17]}$ Tablet formulation of Meclizine $\mathrm{HCl}$ using the 1:1 kneading complex of 2-hydroxypropyl- $\beta$-cyclodextrin with a drug equivalent to $25 \mathrm{mg}$ was prepared using sodium starch glycolate as superdisintegrants, and Pearlitol SD 200 and Avicel PH102 as diluents, aspartame as sweetening agent, and lemon as flavour, by using a direct compression method. Evaluations of precompression and postcompression parameters were performed. A dissolution study of prepared tablets was performed in $0.5 \%$ SLS in water ( $\mathrm{pH} 7.0)$. A comparison study of prepared tablets was done with marketed a Meclizine $\mathrm{HCl} 25 \mathrm{mg}$ conventional tablet.

\section{MATERIALS AND METHODS}

\section{Chemicals}

Meclizine HCl, Sodium Starch Glycolate, Pearlitol SD 200, Avicel PH102, Aspartame, and Lemon were obtained as a gift sample from Unique Pharmaceutical Lab., Mumbai India. HP- $\beta-C D$ and $\beta-C D$ were from Signet Chemical Corporation Pvt. Ltd., Mumbai. All other ingredients and solvent used were of analytical grade.

\section{Phase solubility studies}

The phase-solubility technique permits the evaluation of the affinity between HP- $\beta-C D$ and $\beta-C D$ with Meclizine $\mathrm{HCl}$ in water. It gives not only the solubilising ability of CD's, but also the stability constant of the complexes by analysing the solubility curve. Phase solubility studies were performed according to the method reported by Higuchi and Connors. ${ }^{[18-20]}$ This methodology was based 
on the solubility variation of the guest molecule (drug) upon increase of the host molecule $(\beta-\mathrm{CD} / \mathrm{HP} \beta-\mathrm{CD})$ concentration. Solubility studies were performed by taking excess of drug $(100 \mathrm{mg})$ and added to $50 \mathrm{ml}$ of distilled water containing varying concentration of $\beta-C D(3-15$ $\mathrm{mM}$ ) and HP- $\beta-C D(3-15 \mathrm{mM})$ in a $100 \mathrm{ml}$ screw capped amber coloured bottles. The mixtures were shaken for 48 $\mathrm{h}$ on thermo-statistically controlled shaking water bath at $37 \pm 1^{\circ}$. This amount of time is considered sufficient to reach equilibrium. Subsequently, the aliquots were withdrawn, using a syringe and samples were filtered immediately through a $0.45-\mu \mathrm{m}$ membrane filter (PVDF) and approximately diluted. ${ }^{[21]}$

A portion of the sample was analyzed by a UV spectrophotometer (UV-1700, Shimadzu, Japan) at 232 $\mathrm{nm}$ against a blank prepared in the same concentration of cyclodextrin in water. The solubility experiments were performed in triplicate. The apparent stability constant $\left(K_{c}\right)$ according to the hypothesis of 1:1 stoichiometric ratio of complex was calculated from the phase solubility diagrams using the following equation. ${ }^{[2]}$

$K_{1: 1}=$ slope $/ S_{0}(1-$ slope $)$

The slope was obtained from the initial straight line portion of the plot of Meclizine $\mathrm{HCl}$ concentration against $\mathrm{HP}-\beta$ $\mathrm{CD}$ and $\beta-\mathrm{CD}$, so is the equilibrium solubility of Meclizine $\mathrm{HCl}$ in water.

\section{Preparation of solid inclusion complexes}

The following inclusion complexes of $\mathrm{Meclizine} \mathrm{HCl}$ and HP- $\beta$-CD were prepared at 1:1 molar ratio.

\section{Physical mixture}

The physical mixture (PM) of Meclizine $\mathrm{HCl}$ and $\mathrm{HP}-\beta$ $\mathrm{CD}$ in 1:1 molar ratio was prepared by mixing individually components that had previously been sieved through sieve no 60 .

\section{Kneading method}

Meclizine $\mathrm{HCl}$ and $\mathrm{HP}-\beta-\mathrm{CD}$ in a molar ratio of $1: 1$ was wetted with appropriate quantity of water to form a kneaded-like paste. Several hours of trituration and grinding of paste in a mortar result in evaporation of solvent. The kneading mass thus obtained is dried for $48 \mathrm{~h}$ and pulverized which results in formation of powder-like complex.

\section{Co-precipitation method}

Accurately weighed drug and HP- $\beta-C D$ in a molar ratio of 1:1 were dissolved in 1:1 solution of methanol: water to get a clear solution. The resulting solution was stirred at ambient temperature until complete evaporation of the solvent occurred. The resulting solution were kept in desiccator for $48 \mathrm{~h}$, and then grounded in a ceramic mortar for size reduction and passed through sieve \# 100, which results in formation of a powder-like complex.

\section{Differential scanning calorimetry}

The samples were analyzed by differential scanning calorimetry (DSC) using a Mettler Toledo SR system. The samples (5mg each) were placed into pierced an aluminum container. The studies were performed under a static air atmosphere in the temperature range of $20-400^{\circ} \mathrm{C}$ at a heating rate of $10^{\circ} \mathrm{C} / \mathrm{min}$. The peak temperatures were determined after calibration with the standard.

\section{Fourier transform infrared spectroscopy}

Fourier transform IR spectra were recorded on FT/IR4100 type A. The spectra were recorded for Meclizine $\mathrm{HCl}$, HP- $\beta-C D$, physical mixture, kneaded and co-precipitation system. Samples were prepared in a $\mathrm{KBr}$ disc $(2 \mathrm{mg}$ of the sample in $200 \mathrm{mg} \mathrm{KBr}$ ). The scanning range was $400-4000 \mathrm{~cm}^{-1}$, resolution was $4 \mathrm{~cm}^{-1}$.

\section{In vitro dissolution studies}

The dissolution patterns of the complexes were compared with those of a pure drug. The dissolution studies were performed according to the USP XXIII Dissolution apparatus (LABINDIA), Type-II (paddle). The sample corresponding to $25 \mathrm{mg}$ of Meclizine $\mathrm{HCl}$ was placed into hard gelatin capsules. The dissolution medium was $900 \mathrm{ml}$ of $0.5 \%$ SLS in water ( $\mathrm{pH} 7.0)$. The stirring speed of the paddle was $50 \mathrm{rpm}$, and the temperature was maintained at $37 \pm 0.5^{\circ} \mathrm{C}$. The samples $(5 \mathrm{ml})$ were withdrawn at various time intervals, which was filtered through a 0.45 $\mu \mathrm{m}$ membrane filter (PVDF) and analyzed by a UV spectrophotometer at $232 \mathrm{~nm} \cdot{ }^{[23-25]}$

\section{Formulation of tablets by direct compression method}

All the ingredients in Table 1 were weighed and passed through \# 60 mesh separately. Then, the ingredients were mixed and compressed into a tablet using $9.5 \mathrm{~mm}$ flat-faced punches on a 16 station rotary tablet machine (Cadmach, Manesty).

\section{Evaluation of precompression parameters of powder blend}

Micrometric properties of the powder blend for compression like angle of repose, bulk density, tapped density, \% compressibility, and Hausner ratio were evaluated. ${ }^{[26]}$

Evaluation of postcompression parameters of tablets

The prepared tablets were evaluated for tablet hardness using a Dr. Schleuniger Tablet tester (Pharmatron), friability

Journal of Young Pharmacists Vol 4 / No 4 
Table 1: Formulae of fast dissolving tablets of binary system of Meclizine $\mathrm{HCl}$

\begin{tabular}{lc}
\hline Ingredients & F1 ( mg) \\
\hline Eq. blend of Meclizine & 97.63 \\
HCl & \\
Pearlitol SD200 & 58.57 \\
MCC (Avicel pH 102) & 30 \\
Sodium starch glycolate & 4 \\
Aspartame & 1.5 \\
Lemon flavor & 1.5 \\
Aerosil (0.4\%) & 0.8 \\
Talc (3\%) & 6 \\
Total & $200 \mathrm{mg}$ \\
\hline
\end{tabular}

of a sample of 20 tablets was measured using a Roche friabilator (Electrolab), the weight variation test was done by weighing 20 tablets individually, calculating the average weight and comparing the individual tablet weight to the average weight, disintegration time of the tablet was measured in water $\left(37 \pm 2^{\circ} \mathrm{C}\right)$ according to the disintegration test apparatus with a disk (Electrolab). Dissolution studies were carried out in $900 \mathrm{ml}$ of $0.5 \%$ SLS in water (pH 7.0) by the USP paddle method at $50 \mathrm{rpm}$. Comparison of the dissolution profile of the prepared tablet was done with a marketed Meclizine $\mathrm{HCl} 25 \mathrm{mg}$ conventional tablet. ${ }^{[26,27]}$

\section{RESULTS}

Phase solubility study

The phase solubility profiles obtained for the complex formation between Meclizine HCl- $\beta$-CD system and Meclizine HCl-HP $\beta$-CD system are presented in Figure 1 . This plot showed that the aqueous solubility of drug increase linearly as a function of $\mathrm{HP}-\beta-\mathrm{CD}$ and $\beta-\mathrm{CD}$ concentration. The shape of solubility diagram represents linear host-guest correlation $\left(A_{L}\right.$ Type ${ }^{[28,29]}$ with a slope less than 1 indicating the formation of a 1:1 complex with respect to HP- $\beta-C D$ and $\beta-C D$ concentrations. The apparent stability constant, $K_{c}$, obtained from the slope of linear phase solubility diagram was found to be $370.53 \mathrm{M}^{-1}$ for $\beta$-CD and $453.54 \mathrm{M}^{-1}$ for HP- $\beta-C D{ }^{[30]}$ It was observed that the Meclizine HCl-HP- $\beta-\mathrm{CD}$ system shows greater solubility than the Meclizine $\mathrm{HCl}-\beta-\mathrm{CD}$ system and this may be attributed to the fact that the contact surface and cavity size of HP- $\beta-C D$ are higher than $\beta-C D$ thus, HP $\beta-C D$ is selected for further formulation and evaluation studies.

\section{Differential scanning calorimetry}

Differential scanning calorimetry (DSC) was used to identify the inclusion complex between the drug and HP- $\beta$-CD. Some evidence of inclusion complexation was

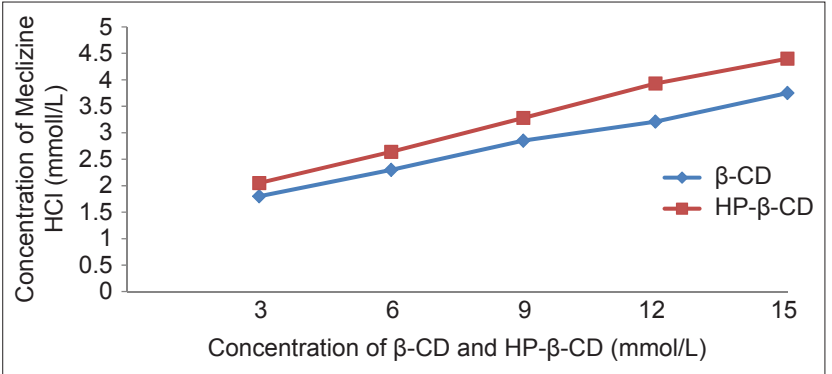

Figure 1: Phase solubility diagram of Meclizine $\mathrm{HCl}$ with $\beta-\mathrm{CD}$ and HP- $\beta-C D$

obtained from thermal analysis. When guest molecules were embedded in HP- $\beta$-CD cavities, their melting, boiling, or sublimation point generally could shift to a different temperature or disappear within the temperature range where HP- $\beta-C D$ was decomposed. As seen from Figure 2, the DSC thermogram of Meclizine $\mathrm{HCl}$ alone showed a sharp endothermic peak at $225^{\circ} \mathrm{C}$, corresponding to the melting point of the drug, while HP- $\beta$-CD showed a very broad endothermic effect, which attained a maximum around $88.06{ }^{\circ} \mathrm{C}$, due to the release of bound water in the cavity [Figure 3]. The endothermic peaks of Meclizine $\mathrm{HCl}$ $\left(191^{\circ} \mathrm{C}\right)$ and $\mathrm{HP}-\beta-\mathrm{CD}\left(99.68^{\circ} \mathrm{C}\right)$ observed in the physical mixture were significantly different from their endotherms in pure forms (lowering of the endothermic peak) indicating that complex formation has taken place only partially that also indicates reduction in drug crystallinity due to complexation [Figure 4]. The same was the case for the complex prepared by a co-precipitation method where endothermic peaks of Meclizine $\mathrm{HCl}\left(180.58^{\circ} \mathrm{C}\right)$ and $\mathrm{HP}-\beta-\mathrm{CD}\left(99.68^{\circ} \mathrm{C}\right)$ were observed [Figure 5], which indicates complex formation is not complete but has taken place to a greater extent. The complete disappearance of the Meclizine $\mathrm{HCl}$ endothermic peak was observed for the inclusion complex prepared by the kneading method [Figure 6], since Meclizine $\mathrm{HCl}$ was contained within the cavity of the HP- $\beta-C D$ ring molecule. ${ }^{[3]}$ This demonstrated that an inclusion complex of Meclizine $\mathrm{HCl}$ could be obtained by the Kneading method.

\section{Fourier transform infrared spectroscopy}

IR spectrum of Meclizine $\mathrm{HCl}$ [Figure 7] is characterized by $3395.32 \mathrm{~cm}^{-1}$ (-N- stretch), $3035.64 \mathrm{~cm}^{-1}$ (CH $=\mathrm{CH}$ stretch aromatic), $2974.35 \mathrm{~cm}^{-1}$ (C-H stretch aliphatic), $2365.49 \mathrm{~cm}^{-1}$ $\left(\mathrm{CH}_{2}-\mathrm{CH}_{2}\right), 1629.97 \mathrm{~cm}^{-1}$ (C $=\mathrm{C}$ stretch), $1486.95 \mathrm{~cm}^{-1}(\mathrm{C}-\mathrm{N}$ stretch), $1192.74 \mathrm{~cm}^{-1}$ (C-Cl stretch). The IR spectrum of pure HP-b-CD [Figure 8] is characterized by prominent peaks at $3412 \mathrm{~cm}^{-1}(\mathrm{O}-\mathrm{H}), 2929.13 \mathrm{~cm}^{-1}(\mathrm{C}-\mathrm{H}), 1645.73 \mathrm{~cm}^{-1}$ ( $\mathrm{H}-\mathrm{O}-\mathrm{H}$ bending), $1032.28 \mathrm{~cm}^{-1}$ (C-O-C). No significant alterations in the IR bands of the pure drug were detected in the physical mixture [Figure 9]. However, some of the 


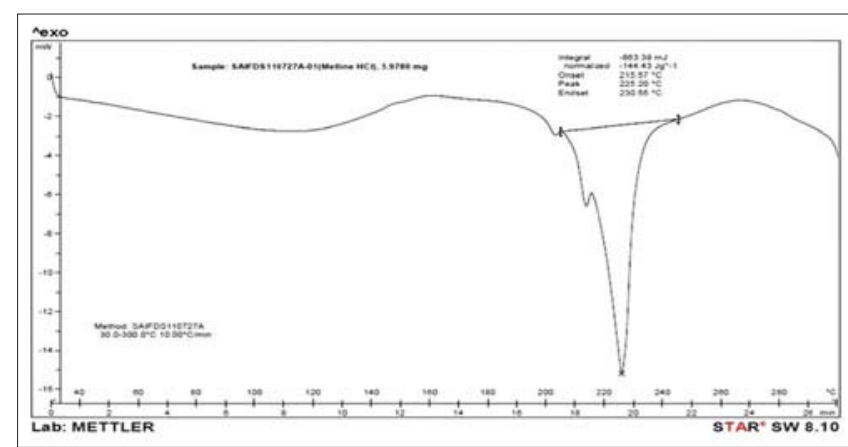

Figure 2: DSC thermogram of Meclizine $\mathrm{HCl}$

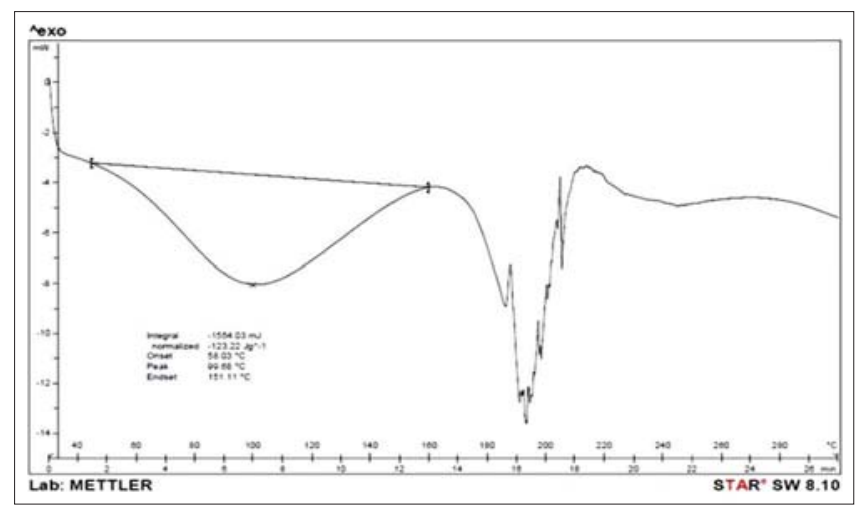

Figure 4: DSC thermogram of physical mixtures

peaks of Meclizine $\mathrm{HCl}$ were slightly shifted and found to be attenuated. The broadening of peak was probably due to the restriction of bending and stretching vibration of the Meclizine $\mathrm{HCl}$ due to the HP- $\beta$-cyclodextrin cavity. The peak of $-\mathrm{N}-$ stretch was found to be disappeared or might be over lapped by $\mathrm{O}-\mathrm{H}$ stretch of HP- $\beta$-CD. However, the IR spectrum of the physical mixture could be diagnosed as a superimposition of the bands of pure drug and HP- $\beta-C D$. Significant changes were recorded in the IR spectrum of the inclusion complex prepared by the kneading [Figure 10] and co-precipitation method [Figure 11]. Almost all peaks of Meclizine $\mathrm{HCl}$ were smoothened indicating a strong physical interaction between pure drug and HP- $\beta-C D$. However, the broad peak of $\mathrm{O}-\mathrm{H}$ of $\mathrm{HP}-\beta-\mathrm{CD}$ was consistently appeared in binary systems. The peak of HP- $\beta-C D$ at $1645.73 \mathrm{~cm}^{-1}$ due to water of crystallization was disappeared which might be because of the replacement of water molecules by Meclizine $\mathrm{HCl}$ inside the $\mathrm{HP}-\beta-\mathrm{CD}$ cavity indicating the formation of the inclusion complex in the solid state. All the binary systems of Meclizine HCl-HP- $\beta$-CD did not show any new peaks, indicating noncovalent interaction in inclusion complex. ${ }^{[32]}$

\section{Drug content}

The HPLC method with a UV-detector was used to determine the drug content of the binary system of the HP- $\beta$-CD: Meclizine $\mathrm{HCl}$ molar ratio of 1:1, in all system

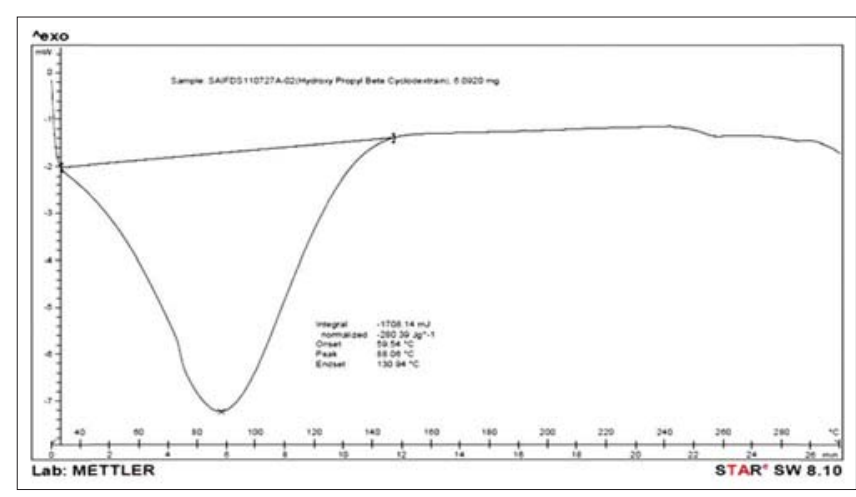

Figure 3: DSC thermogram of HP- $\beta-C D$

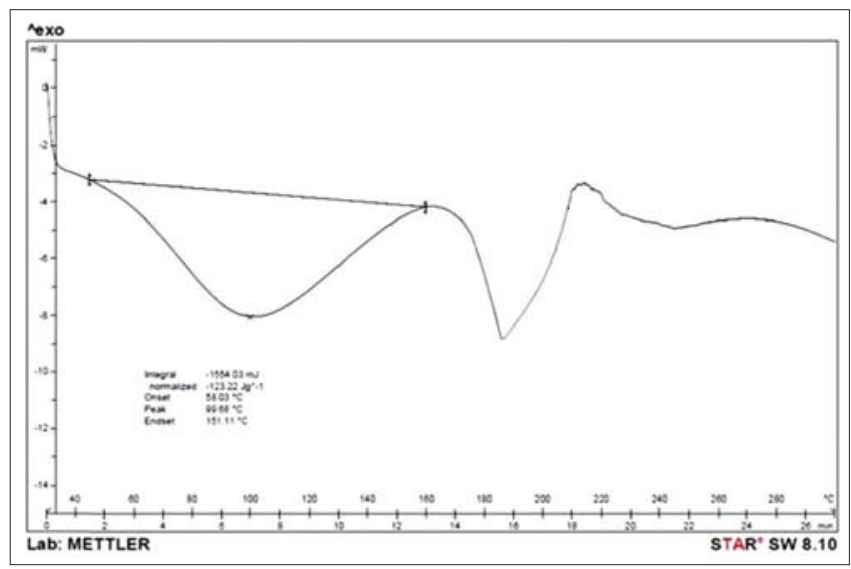

Figure 5: DSC thermogram of the co-precipitation complex

samples of the binary system (equivalent to about $50 \mathrm{mg}$ of Meclizine $\mathrm{HCl}$ ), were dissolved in the mobile phase (1-heptanesulfonic acid) which was diluted to obtain $0.1 \mathrm{mg} / \mathrm{ml}$. The HP- $\beta$-CD drug ratio would therefore remain $1: 1$ in the final solution to calculate the drug content. The drug content in all the system was found to be $99.42-102.36 \%$.

In vitro dissolution studies

The release rate profile was drawn as the cumulative percent release on the $y$-axis and time on the $x$-axis shown in Figure 12. It showed that the inclusion complex of Meclizine $\mathrm{HCl}$ prepared by the kneading method released $79 \%$ drug in $10 \mathrm{~min}$, and up to $95 \%$ drug in $30 \mathrm{~min}$ while the inclusion complex prepared by the co-precipitation method showed $73 \%$ drug release in $10 \mathrm{~min}$ and up to $90 \%$ drug release in $30 \mathrm{~min}$. Physical mixtures show release up to $60 \%$ in $10 \mathrm{~min}$ and up to $80 \%$ drug release in $30 \mathrm{~min}$, whereas the pure drug exhibited the release of $25 \%$ in $10 \mathrm{~min}$ and $55 \%$ drug release in 30min. ${ }^{[32]}$ It was evident that the complex exhibited the faster dissolution rate than $\mathrm{Meclizine} \mathrm{HCl}$ alone. The very high increase of Meclizine $\mathrm{HCl}$ dissolution rate in the case of inclusion complex might be due to several reasons. The formation of soluble inclusion complex, amorphization of 


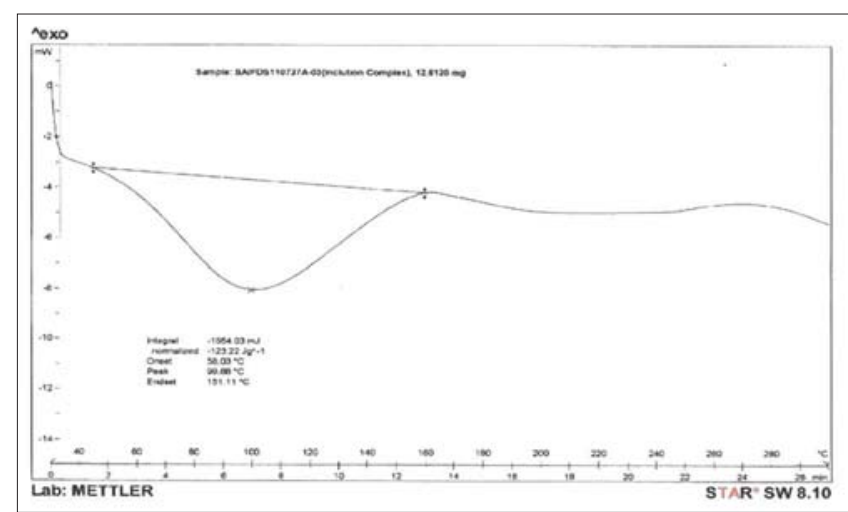

Figure 6: DSC thermogram of the kneading complex

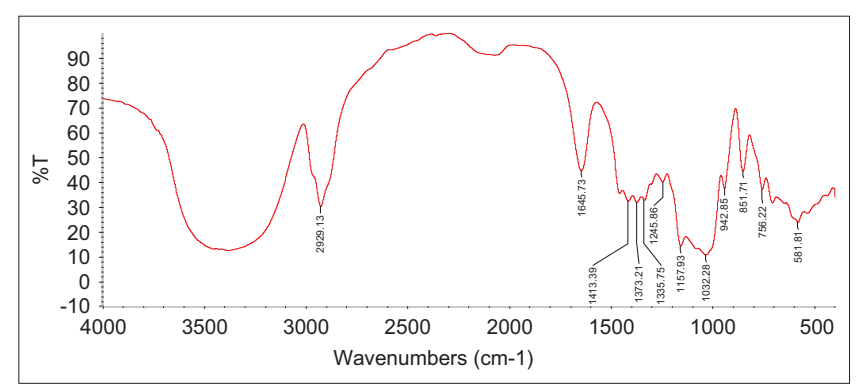

Figure 8: FT-IR spectra of HP- $\beta-C D$

drug and consequently solubility increase, better wettability and reduction of particle size.

Evaluation of precompression parameters of powder blend

The angle of repose of the powder blend was found to be $29.58^{\circ}$. The bulk density, tapped density, $\%$ compressibility and Hausner's ratio were found to be $0.625 \mathrm{~g} / \mathrm{cm}^{3}$, $0.714 \mathrm{~g} / \mathrm{cm}^{3}, 12.46 \%$, and $1.142 \%$, respectively.

Evaluation of postcompression parameters of tablets

The hardness of the prepared tablet was found to be $3.3 \pm 0.22 \mathrm{~kg} / \mathrm{cm}^{2}$. Friability was found to be $0.51 \%$, which were below $1 \%$ indicating sufficient mechanical integrity and strength of prepared tablets. The disintegration time was found to be $58.34 \pm 0.57 \mathrm{~s}$. Weight variation was found to be $200.21 \pm 3.434 \mathrm{mg}$ which was within the permissible limit of $\pm 7.5 \%$. The in vitro dissolution studies showed that almost $69 \%$ of the drug was released within $10 \mathrm{~min}$ and almost $96 \%$ of the drug was released at the end of $30 \mathrm{~min}$. The prepared tablets were compared with the marketed tablet, and the dissolution parameters of both formulations are shown in Table 2 and Figure 13. The drug content was found to be $98.54 \%$.

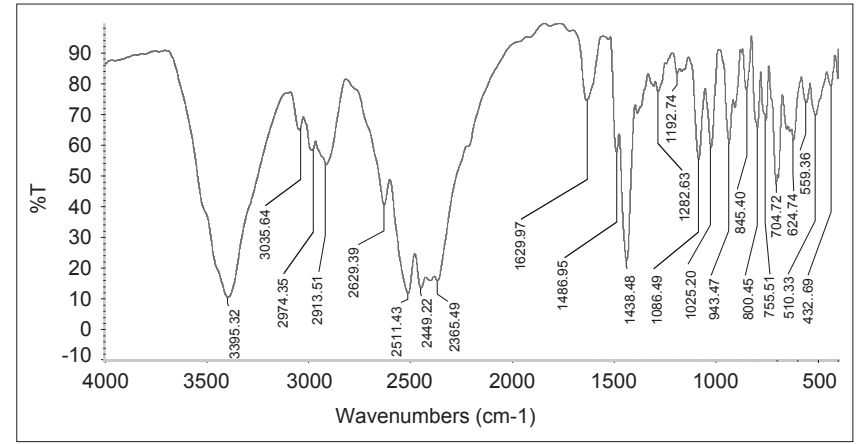

Figure 7: FT-IR spectra of Meclizine $\mathrm{HCl}$

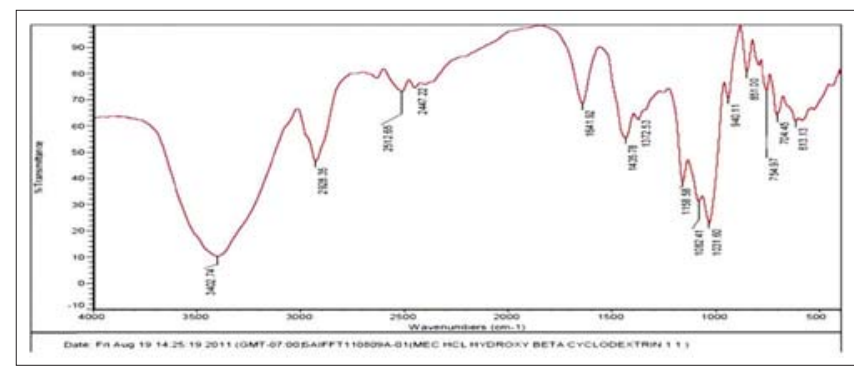

Figure 9: FT-IR spectra of physical mixture

Table 2: Comparison of dissolution data of prepared tablet and marketed tablet

\begin{tabular}{lcc}
\hline Time (min) & $\begin{array}{c}\text { \% Release from } \\
\text { prepared tablet }^{\text {a }}\end{array}$ & $\begin{array}{c}\text { \% Release from } \\
\text { marketed tablet }^{\mathrm{a}}\end{array}$ \\
\hline 5 & $44.44 \pm 0.61$ & $3.49 \pm 0.32$ \\
10 & $68.28 \pm 0.46$ & $9.87 \pm 0.23$ \\
15 & $72.34 \pm 0.64$ & $22.43 \pm 0.93$ \\
20 & $78.31 \pm 0.48$ & $28.98 \pm 0.34$ \\
25 & $84.12 \pm 0.46$ & $34.93 \pm 0.94$ \\
30 & $95.16 \pm 0.64$ & $53.39 \pm 0.45$ \\
45 & - & $70.39 \pm 0.50$ \\
60 & - & $81.39 \pm 0.49$ \\
\hline${ }^{2}$ Mean \pm SD, $n=3$ &
\end{tabular}

\section{DISCUSSION}

From the result it is observed that the solubility of Meclizine $\mathrm{HCl}$ in the presence of $\beta$-cyclodextrin and $\mathrm{HP}-\beta-\mathrm{CD}$ can be classified as the $A_{L}$ type. This indicated that the complexes at 1:1 ratio are adequately stable and also the extent of solubility enhancement being higher for HP- $\beta-C D$. The DSC thermogram for the physical mixture showed the persistence of the endothermic peak of Meclizine $\mathrm{HCl}$. Though there is reduction in peaks intensity, this can be explained on the basis of major interaction between the drug and HP- $\beta-C D$. Furthermore, the characteristic endothermic effect of HP- $\beta$ $\mathrm{CD}$ and $\mathrm{Meclizine} \mathrm{HCl}$ is slightly shifted to lower temperature for the physical mixture indicating partial complexes formation, i.e. some parts of Meclizine $\mathrm{HCl}$ entrapped in HP- $\beta-C D$ cavity. The enhancement in the dissolution profile has been attributed due to the formation of inclusion 


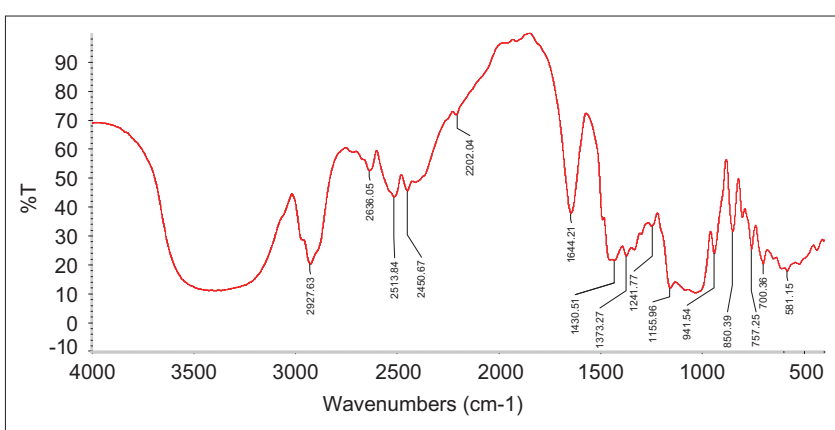

Figure 10: FT-IR spectra of the kneading method

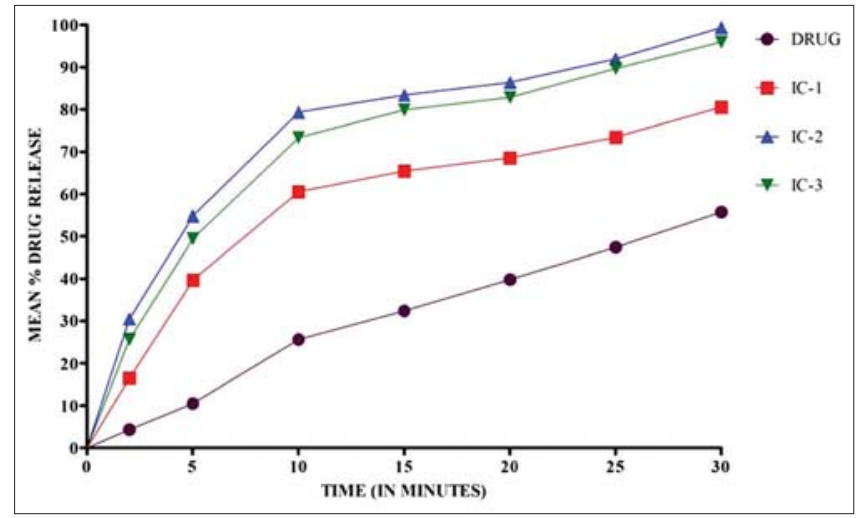

Figure 12: Dissolution rate profile of Meclizine $\mathrm{HCl}-\mathrm{HP}-\beta-\mathrm{CD}$ systems

complexes in the solid state and reduction in the crystallinity of the product. While the DSC thermogram of the kneading complex shows the complete disappearance of the Meclizine $\mathrm{HCl}$ endothermic peak and flattening of endotherm which indicates the formation of true complex and conversion of a drug-to-amorphous form, a small exothermic peak was obtained is due to the recrystallization of some drugs. The dissolution rate increase for the physical mixture, kneaded and co-precipitation mixtures is due to the wetting effect of the HP- $\beta-C D$, this effect is more evident for the kneaded product, where the mixing process between the two components is more intensive. The effect of complexation with HP- $\beta-C D$ on the solubility of Meclizine $\mathrm{HCl}$ can be explained in terms of the reduction in the crystallinity of the drug and conversion to amorphous form by inclusion into the hydrophobic cavity of the HP- $\beta$-CD. The FTIR spectra of the physical mixture showed no significant alterations in the IR bands of the pure drug. However, some of the peaks of $\mathrm{Meclizine} \mathrm{HCl}$ were slightly shifted and found to be attenuated. The broadening of peak was probably due to the restriction of bending and stretching vibration of the Meclizine $\mathrm{HCl}$ due to the $\mathrm{HP}-\beta$ CD cavity. However, the IR spectrum of the physical mixture could be diagnosed as a superimposition of the bands of the pure drug. Significant changes were recorded in the IR spectrum of the inclusion complex. Almost all peaks of Meclizine $\mathrm{HCl}$ were smoothened indicating strong physical

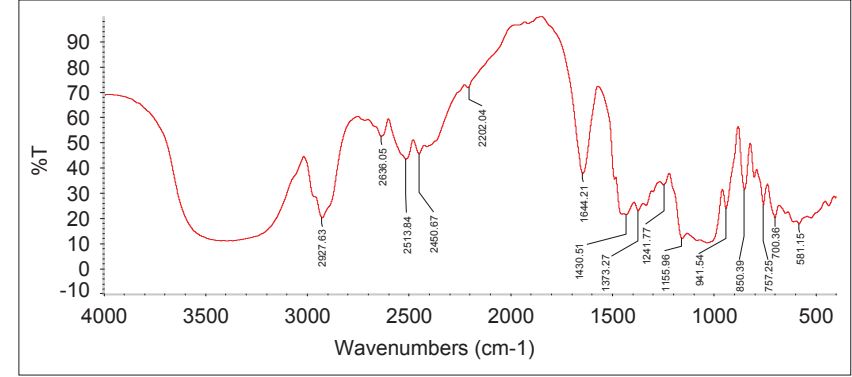

Figure 11: FT-IR spectra of co-precipitation

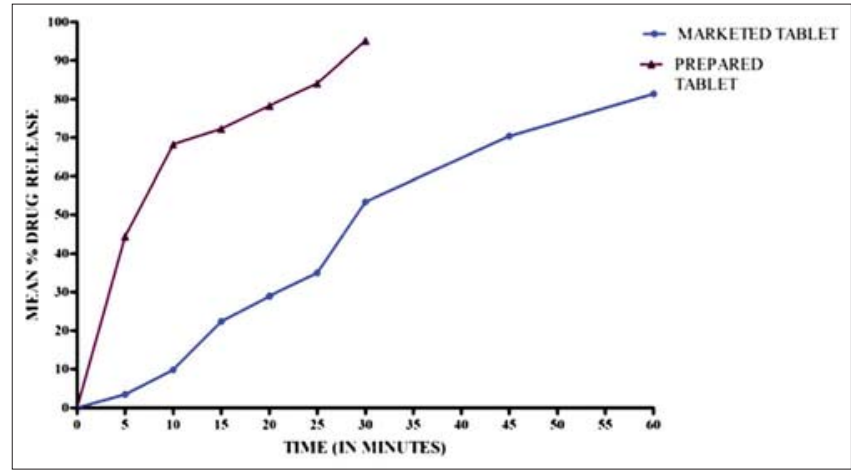

Figure 13: Comparison of dissolution profiles of the prepared tablet and marketed tablet

interaction between pure drug and HP- $\beta-C D$, indicating the formation of inclusion complex in the solid state. All the binary systems of Meclizine $\mathrm{HCl}-\mathrm{HP}-\beta-\mathrm{CD}$ did not show any new peaks, indicating noncovalent interaction in the inclusion complex. In vitro drug release from prepared tablets shows significantly improved drug dissolution as compared to the marketed tablet of Meclizine $\mathrm{HCl}$. Hence, it could be concluded that the solubility enhancement of Meclizine $\mathrm{HCl}$ could be successfully achieved by the inclusion complexation technique and inclusion complex based fast dissolving tablets of Meclizine $\mathrm{HCl}$ would provide quick-onset of action.

\section{ACKNOWLEDGMENTS}

The authors are grateful to Dr. Amarjeet Singh, General Manager, Formulation and Development Department (RandD) of J.B. Chemicals and Pharmaceuticals Limited, Mumbai, for providing guidance and facilities to carry out the research work. They are also thankful to the analytical development department of J.B Chemicals and Pharmaceuticals Limited, Mumbai, for providing facility and guidance in doing analysis.

\section{REFERENCES}

1. Oosterveld WJ. Vertigo: Current concepts in management. Drugs 1985;30:275-83.

2. MHCL. Available from: http: \www.drugbank.com. [Last accessed on 2011 Oct 25].

3. The Pharmaceutical Codex. 11th ed. Pharmaceutical Society of Great Britain; 1979. p. 518. 
4. Jain NK. Progress in controlled and novel drug delivery system. Drug Deliv Syst 2004;1:384-400.

5. Loftson T, Brewster ME. Pharmaceutical applications of cyclodextrins, drug solubilization and stabilization. J Pharm Sci 1996;59:1601-8.

6. Duchene D, Wouessidjewe D. Physiochemical characteristics and pharmaceutical uses of cyclodextrin derivatives, Part II. Pharm Technol 1990;14:26-34.

7. Challa R, Ahuja A, Ali J, Khar R. Cyclodextrins in drug delivery: An updated review. AAPS PharmSciTech 2005;6:329-57.

8. Carrier RL, Miller LA, Ahmed I. The utility of cyclodextrins for enhancing oral bioavailability. J Control Rel 2007;123:78-99.

9. Odak SP, Gidwani SK. Enhancement of aqueous solubility of levodopa by using 2-HP- $\beta$-cyclodextrin. Int J Pharm Sci 2011;3:933-8.

10. Ahmed MO. Comparison of impact of the different hydrophilic carriers on the properties of piperazine-containing drug. Eur J Pharm Biopharm 2001;51:221-6.

11. Pose-Vilarnovo B, Perdomo-López I, Echezarreta-López M, Schroth- Pardo P, Estrada E, Torres-Labandeira JJ. Improvement of water solubilityof sulfamethizole through its complexation with $\beta$ - and Hydroxypropyl$\beta$-cyclodextrin Characterization of the interaction in solution and in solid state. Eur J Pharm Sci 2001;13:325-31.

12. Maski N, Kumaran A, Girhepunje K, Ghode P, Randive S, Pal R. Studies on the preparation, characterization and solubility of $\beta$-cyclodextrin-diacerein inclusion complexes. Int J Pharm Pharm Sci 2009;1:121-35.

13. Zeng J, Ren Y, Zhou C, Yu S, Chen WH. Preparation and physicochemical characteristics of the complex of edaravone with Hydroxypropyl- $\beta$ cyclodextrin. Carbohy Dr. Polym 2011;83:1101-5.

14. Ling W, Xuehua J, Weijuan X, Chenrui L. Complexation of Tanshinone IIA with 2-hydroxypropyl- $\beta$-cyclodextrin: Effect on aqueous solubility, dissolution rate, and intestinal absorption behaviour in rats. Int J Pharm 2007;341:58-67.

15. Derle D, Boddu SH, Mager M. Studies on the preparation, characterization and solubility of $\beta$-cyclodextrin-starnidazole inclusion complexes. Indian J Pharma Educ Res 2006;40:232-6.

16. Baboota S, Dhariwal M, Kohli K. Physicochemical charactrization, in vitro dissolution behaviour and phamacodynamic studies of refecoxibcyclodextrin inclusion compound. Preparation and properties of refecoxib hydroxypropyl $\beta$-cyclodextrin inclusion complex. AAPS Pharma Sci Tech 2005;6:83-90.

17. Manca ML, Zaru M, Ennas G, Valenti D, Sinico C, Lov G, et al. Diclofenac - $\beta$-cyclodextrin binary system: Physicochemical characterization and invitrodissolution and diffusion studies. AAPS PharmaSciTech 2005;6:464-72.

18. Higuchi T, Connors KA. Phase solubility techniques. Adv Anal Chem Instrum 1965;4:117-212.
19. Higuchi T, Kristiansen H. Binding specificity between small organic solutes in aqueous solution, classification of some solutes into two groups according to binding tendencies. J Pharm Sci 1970;59:1601-8.

20. Zughul MB, Badwan AA. Rigorous analysis of S2L- type phase solubility diagrams to obtain individual formation and solubility product constants of both SL- and S2L- type complexes. Int J Pharm 1997;151:109-19.

21. Marques HC, Hadgraft J, Kllaway I. Studies of cyclodextrin inclusion complexes; The salbutamol-cyclodextrin complex as studies by phasesolubility and DSC. Int J Pharm 1990;63:259-60.

22. Tirucherai GS, Mitra AK. Effect of hydroxypropyl beta cyclodextrin complexation on aqueous solubility, stability, and corneal permeation of acyl ester prodrugs of ganciclovir. AAPS PharmSciTech 2003;45:1-12.

23. Klancke J. Dissolution testing of orally disintegrating tablets. Dissolution Technol 2003:1 6-8.

24. Patil PB, Gupta VR, Udupi RH, Srikanth K, Prasad BS. Development of dissolution medium for poorly water soluble drug mefenamic acid. Research Journal of Pharmaceutical, Biological and Chemical Sciences 2010;1:544-9.

25. Singla N, Gupta GD, Kohli K, Singla AK. A discriminatory and biorelevant dissolution test method for simvastatin drug products. Dissolution Technol 2009;3:11-13.

26. Jain CP, Naruka PS. Formulation and evaluation of fast dissolving tablets of alsartan. Int J Pharm Pharm Sci 2009;1:219-26.

27. Patel B, Patel D, Parmar R, Patel C, Serasiya T, Sanja SD. Development and in vitro evaluation of fast dissolving tablets of glipizide. Int $\mathrm{J}$ Pharm Pharm Sci 2009;1:145-50.

28. Miyazawa I, Ueda H, Nagase H, Endo T, Kobayashi S, Nagai T. Physicochemical properties and inclusion complex formation of ס-cyclodextrin. Eur J Pharm Sci 1995;3:153-62.

29. Chowdhery KP, Vijaya SS. Effect of polyvinylpyrrolidone on complexation and dissolution rate of $\beta$-cyclodextrin and hydroxypropyl $\beta$-cyclodextrin complexes of celecoxib. Indian J Pharm Sci 2006;68:631-4.

30. Giordano F, Novak C, Moyano JR. Thermal analysis of cyclodextrins and their inclusion compounds. Thermochim Acta 2001;380:123-51.

31. Veiga F, Fernandes C, Maincent P. Influence of the preparation method on the physicochemical properties of tolbutamide/cyclodextrin binary system. Drug Dev Ind Pharm 2001;27:523-32.

32. Varia U, Patil C, Kalyane N, Agrawal P. Effect of cyclodextrin inclusion complex on dissolution behaviour of cefixime. J Pharm Res 2010;3:570-4

How to cite this article: George SJ, Vasudevan DT. Studies on the preparation, characterization, and solubility of 2-HP- $\beta$-cyclodextrin-meclizine hcl inclusion complexes. J Young Pharmacists 2012;4:220-7.

Source of Support: Nil, Conflict of Interest: None declared.

\section{“QUICK RESPONSE CODE” LINK FOR FULL TEXT ARTICLES}

The journal issue has a unique new feature for reaching to the journal's website without typing a single letter. Each article on its first page has a "Quick Response Code". Using any mobile or other hand-held device with camera and GPRS/other internet source, one can reach to the full text of that particular article on the journal's website. Start a QR-code reading software (see list of free applications from http://tinyurl.com/yzlh2tc) and point the camera to the QR-code printed in the journal. It will automatically take you to the HTML full text of that article. One can also use a desktop or laptop with web camera for similar functionality. See http://tinyurl.com/2bw7fn3 or http://tinyurl.com/3ysr3me for the free applications. 